Revista Multidisciplinar do Nordeste Mineiro, v.2

\title{
A IMPORTÂNCIA DO RECEITUÁRIO AGRONÔMICO PARA O USO SEGURO E LEGAL DE PRODUTOS AGROTÓXICOS
}

THE IMPORTANCE OF THE AGRONOMIC RECIPIENT FOR THE SAFE AND LEGAL USE OF AGRICULTURAL PRODUCTS

\author{
Kárisma Rodrigues Pêgo \\ Graduando,Faculdade Presidente Antonio Carlos,Brasil \\ Ítalo Antunes pereira Lima \\ Orientador,Faculdade Presidente Antonio Carlos,Brasil
}

Recebido: 20/05/2021 - Aceito: 20/05/2021 


\section{RESUMO}

Os agrotóxicos são produtos químicos destinados à utilização pela agricultura com a finalidade de combater às pragas ou destinados a aumentar a produtividade de determinadas culturas. Estes produtos são classificados em três classes principais que são os inseticidas, os quais possuem ação de combate a insetos, larvas e formigas; fungicidas, que atuam no combate a fungos; herbicidas que são aqueles que apresentam ação sobre plantas invasoras. O Brasil apresenta uma taxa de utilização superior à de outros grandes produtores agrícolas, tendo como referência os Estados Unidos, as quantidades nos dois países são próximas, cada um respondendo por cerca de $10 \%$ do consumo mundial. Com o crescimento acentuado da utilização de produtos químicos na lavoura brasileira, na década de 70 profissionais de saúde e defensores do meio ambiente, agrônomos, consumidores, agricultores e ecologistas, começaram a pressionar o Congresso Nacional pela criação de uma lei em matéria de agrotóxicos. Segundo a Lei, a compra destes produtos só pode ocorrer com a apresentação do chamado Receituário Agronômico, que é um instrumento disponibilizado para controlar o uso indiscriminado dos agrotóxicos, preservando assim o meio ambiente e ao mesmo tempo contribuindo com a saúde dos usuários.

\section{Palavras-chave: Agrotóxicos. Regulamentação. Receituário agronômico}

\section{ABSTRACT}

Pesticides are chemical products intended for use in agriculture to combat pests or to increase the productivity of certain crops. These products are classified into three main classes, which are insecticides, which have action to combat insects, larvae and ants; fungicides, which act to combat fungi; herbicides that are those that act on invasive plants. Brazil has a higher utilization rate than other large agricultural producers, with reference to the United States, the quantities in the two countries are close, each accounting for about $10 \%$ of world consumption. With the sharp growth in the use of chemicals in Brazilian farming, in the 70s health professionals and environmental advocates, agronomists, consumers, farmers and ecologists, began to pressure the National Congress for the creation of a law on pesticides. According to

\footnotetext{
${ }^{1}$ Aluna do $10^{\circ}$ Período do Curso de Agronomia da Faculdade Presidente Antônio Carlos de Teófilo Otoni/MG UNIPAC/TO. Email: kharysma.ity@ hotmail.com.

${ }^{2}$ Professor Orientador do curso de Agronomia da Faculdade Presidente Antônio Carlos de Teófilo Otoni/MG UNIPAC/TO. Engenhiro Agrônomo. MSc. Fisiologia Vegetal.
} 


\section{$2021 / 02$}

ISSN 2178-6925

the Law, the purchase of these products can only occur with the presentation of the so-called Agronomic Receipt, which is an instrument made available to control the indiscriminate use of pesticides, thus preserving the environment and the same time contributing to the health of users.

Keywords: Pesticides. Regulation. Agronomic prescription

\section{INTRODUÇÃO}

O crescimento populacional provocou um aumento natural na demanda por alimentos e automaticamente pela matéria prima de produção deste, exigindo assim uma maior produtividade da agricultura e pecuária.

Este aumento exigiu o uso de tecnologias e produtos mais agressivos, como fertilizantes e principalmente agrotóxicos, destinado ao combate de pragas e ao aumento da produção em determinadas culturas.

O uso destes produtos cresceu exponencialmente, exigindo intervenções legais que pudessem controlar ou regular sua aplicação, no intuito de proteger tanto o meio ambiente, quanto a saúde do ser humano.

Neste sentido, o trabalho em questão tem por objetivo demonstrar que o receituário agronômico é um instrumento legal para o controle e uso seguro dos agrotóxicos.

A abordagem deste tema apresenta uma importante relevância ao meio acadêmico como papel informativo aos futuros profissionais da área, e também para sociedade em geral, para se conscientizar sobre os riscos do uso ilegal e indiscriminado dos produtos.

Em termos metodológicos, o trabalho foi desenvolvido através de uma pesquisa exploratória e descritiva com o intuito de levantar informações acumuladas e sistematizadas, através da revisão de literatura disponível sobre o tema exposto, através de um levantamento bibliográfico em livros de leitura corrente e periódicos eletrônicos disponíveis em bases nacionais.

\section{A AGROPECUARIA NA PRODUÇÃO DOS ALIMENTOS}

Os alimentos básicos, fonte de carboidratos e de proteínas são basicamente os 
Revista Multidisciplinar do Nordeste Mineiro, v.2 $2021 / 02$

ISSN 2178-6925

mesmos, sejam de origem vegetal (grãos, raízes e tubérculos, oleaginosas e 
frutas) ou animal (carnes de suínos, aves e bovina, leite, ovos e peixes). Os mais importantes são os grãos (principalmente arroz, trigo, milho, centeio, sorgo, cevada, milheto e triticale) que ocupam uma grande área de cultivos, responsáveis por $66 \%$ da alimentação mundial e largamente produzido em vários países, desde os tempos mais remotos. Dos alimentos raízes e tubérculos o mais importante é a mandioca, com área colhida mundial de mais de 18 milhões de hectares. Das oleaginosas utilizada na alimentação, tanto humana como animal, as mais importantes são soja, dendê, girassol, algodão e coco. Os alimentos de origem animal, principais fontes de proteína na dieta alimentar são as carnes (suína, bovina e de aves), peixes, leite e ovos (SCOLARI, 2008).

Com a expansão populacional, evidencia-se uma grande demanda por estes alimentos e matérias- primas que impulsionam o desenvolvimento de tecnologias que sejam capazes de promover a produção de alimentos em maior escala.

O Brasil é considerado um dos países que apresentam condições de aumentar a produção agropecuária para suprir a demanda mundial por alimentos e biocombustíveis. Entretanto, muitos obstáculos ainda precisam ser vencidos para que esse crescimento do setor agropecuário ocorra de uma maneira sustentável, gerando não apenas benefícios econômicos para o país, mas também garantindo a conservação da sua grande riqueza de recursos naturais e proporcionando melhores condições de vida para o homem do campo. É importante destacar que os serviços ambientais fornecidos por esses recursos, além de essenciais para o bem-estar de toda a população brasileira, são também fundamentais para a continuidade da própria produção agropecuária do país, a exemplo do serviço realizado pelos polinizadores (SAMBUICHI et al, 2012).

O setor agropecuário vem se destacando na economia brasileira nas últimas décadas por seu expressivo aumento em produtividade e sua crescente importância para a manutenção do equilíbrio da balança comercial do país. Com a modernização da agricultura e o aumento do uso intensivo de máquinas e insumos, elevaram-se os níveis de produtividade da terra e do trabalho, contribuindo também para o crescimento da indústria associada ao setor (GASQUES et al., 2010).

Estima-se que a produção do agronegócio brasileiro, que inclui toda a produção resultante das atividades agropecuárias e das indústrias a montante e a jusante desse processo produtivo, responda atualmente por $22,7 \%$ do Produto Interno Bruto (PIB) 
Revista Multidisciplinar do Nordeste Mineiro, v.2 2021/02

ISSN 2178-6925

brasileiro (CEPEA, 2011). 


\section{1/02}

ISSN 2178-6925

A agropecuária brasileira sempre trabalhou num contexto de abertura ao resto do mundo, operando de forma concorrencial. Nesse contexto, o País transformou-se num grande player global, cada vez mais relevante. Em 1990, o saldo da balança agrícola, medido em dólares, foi de US\$ 7 bilhões (dados da World Trade Organization - WTO), número que, até 2011, cresceu dez vezes, atingindo US\$ 73 bilhões, expansão muito maior do que a de qualquer outra nação. Isso também tem efeito macroeconômico destacado, uma vez que a balança comercial agrícola em 2013 foi de 83 bilhões de dólares, enquanto o saldo total foi de apenas 3 bilhões. O País é um dos quatro maiores exportadores de açúcar, soja, milho, suco de laranja, café, algodão, suínos, aves e bovinos (EMBRAPA, 2014).

A manutenção deste patamar exige cada vez mais uma produtividade constante, entretanto, os atuais ganhos de produtividade do setor vêm se baseando principalmente no uso de tecnologias muito agressivas ao ambiente, com a predominância da monocultura e do uso maciço de agroquímicos (SAMBUICHI et al, 2012).

Corrobora Tavella et al (2011), que o Brasil é um dos poucos, entre os grandes produtores agrícolas mundiais, que reúne características como competitividade e área disponível para prover a demanda de alimentos, fibras e energia renovável no mundo, porém, neste cenário não se pode negar que em qualquer atividade agrícola, especialmente na produção de cereais, a atividade somente será competitiva quando atingir elevado nível de tecnologia em toda cadeia produtiva com a finalidade de baixar o custo final de produção, no entanto, lamentavelmente inserido neste "pacote tecnológico", a utilização de produtos agrotóxicos tem sido crescente

Por isso, Atualmente, os sistemas de produção da agropecuária brasileira apresentam realidade complexa: por um lado, a expansão da fronteira de ocupação e, por outro, as áreas consolidadas de agricultura moderna, baseadas no uso intensivo de máquinas, fertilizantes e agrotóxicos.

O homem ainda não conseguiu desenvolver agropecuária estável que capaz de suportar o crescimento populacional sem provocar danos ao meio ambiente, por isso, cada vez mais são utilizados excessivas quantidades de produtos químicos tóxicos, sendo que alguns nem atendem as especificações necessárias e por ter menor preço, favorece o uso indiscriminado e provoca maiores danos ao ecossistema (MELO et al, 2010). 


\title{
3 AGROTÓXICOS: CONCEITO E CLASSIFICAÇÃO
}

Os agrotóxicos são conceituados por Antunes (2015), como produtos químicos destinados à utilização pela agricultura com a finalidade de combater às pragas ou destinados a aumentar a produtividade de determinadas culturas. Inicialmente, foram denominadas como fertilizantes ou defensivos agrícolas, denominações estas que caíram em desuso, tendo em vista a adoção de nova denominação pela lei brasileira.

Segundo o artigo $2^{\circ}$ da lei $7.802,5$ de 11 de julho de 1989 , considera agrotóxicos e afins como sendo:

Art. 2ำ Para os efeitos desta Lei, consideram-se:

I - agrotóxicos e afins:

a) os produtos e os agentes de processos físicos, químicos ou biológicos, destinados ao uso nos setores de produção, no armazenamento e beneficiamento de produtos agrícolas, nas pastagens, na proteção de florestas, nativas ou implantadas, e de outros ecossistemas e também de ambientes urbanos, hídricos e industriais, cuja finalidade seja alterar a composição da flora ou da fauna, a fim de preservá-las da ação danosa de seres vivos considerados nocivos;

b) substâncias e produtos, empregados como desfolhantes, dessecantes, estimuladores e inibidores de crescimento;

Por sua vez, o inciso IV, do artigo 1ํㅡㄹ do decreto 4.074,6 de 4 de janeiro de 2002, que regulamenta a aludida lei, dispõe que:

\begin{abstract}
Art. 10
Para os efeitos deste Decreto, entende-se por:

[...]

IV - agrotóxicos e afins - produtos e agentes de processos físicos, químicos ou biológicos, destinados ao uso nos setores de produção, no armazenamento e beneficiamento de produtos agrícolas, nas pastagens, na proteção de florestas, nativas ou plantadas, e de outros ecossistemas e de ambientes urbanos, hídricos e industriais, cuja finalidade seja alterar a composição da flora ou da fauna, a fim de preservá-las da ação danosa de seres vivos considerados nocivos, bem como as substâncias e produtos empregados como desfolhantes, dessecantes, estimuladores e inibidores de crescimento [...].
\end{abstract}

Assim, pode-se afirmar que os agrotóxicos são compostos que apresentam grande variedade de substâncias químicas utilizadas para matar, exterminar e combater as pragas agrícolas, ou seja, são venenos agrícolas de evidente toxidade ao meio ambiente e à saúde humana.

Os agrotóxicos são classificados conforme o organismo alvo e grupo químico, conforme a sua toxicidade e conforme a sua periculosidade ambiental. 


\section{$2021 / 02$}

ISSN 2178-6925

De acordo com Karan et al (2015), conforme o organismo alvo ou finalidade, estes produtos são classificados em três classes principais que são os inseticidas, os quais possuem ação de combate a insetos, larvas e formigas; fungicidas, que atuam no combate a fungos; herbicidas que são aqueles que apresentam ação sobre plantas invasoras. A classificação de acordo com o grupo químico e o tipo de ação é apresentada conforme o quadro abaixo (quadro 1):

Quadro 1: Principais categorias de agrotóxicos quanto á sua ação e ao grupo químico ao qual pertencem

\begin{tabular}{|c|c|c|}
\hline \multicolumn{2}{|c|}{ Classificação quanto à Classificação quanto } & $\begin{array}{c}\text { Exemplos } \\
\text { (produto/substâncias/agentes) }\end{array}$ \\
\hline \multirow{6}{*}{$\begin{array}{l}\text { Inseticidas } \\
\text { (controle de } \\
\text { insetos) }\end{array}$} & Inorgânicos & $\begin{array}{l}\text { Fosfato de alumínio, arsenato de } \\
\text { cálcio }\end{array}$ \\
\hline & Extratos vegetais & Oleos vegetais \\
\hline & Organoclorados & Aldrin, ${ }^{*} \mathrm{DDT},{ }^{\star} \mathrm{BHC}^{*}$ \\
\hline & Organofosforados & $\begin{array}{l}\text { Fenitrotion, Paration, Malation, } \\
\text { Metil-paration }\end{array}$ \\
\hline & Carbamatos & Carbofuran, Aldicarb, Carbaril \\
\hline & $\begin{array}{l}\text { Piretróides sintéticos } \\
\text { Microbiais }\end{array}$ & $\begin{array}{l}\text { Deltametrina, Permetrina } \\
\text { Bacillus thuringiensis }\end{array}$ \\
\hline \multirow{5}{*}{$\begin{array}{l}\text { Fungicidas } \\
\text { (combate aos } \\
\text { fungos) }\end{array}$} & Inorgânicos & Calda Bordalesa, enxofre \\
\hline & Ditiocarbamatos & Mancozeb, Tiram, Metiram \\
\hline & Dinitrofenóis & Binapacril \\
\hline & $\begin{array}{l}\text { Organomercuriais } \\
\text { Antibióticos Trifenil } \\
\text { estânico } \\
\text { Compostos Formilamina }\end{array}$ & $\begin{array}{l}\text { Acetato de fenilmercúrio } \\
\text { Estreptomicina, Ciclo-hexamida } \\
\text { Duter, Brestam } \\
\text { Triforina, Cloraniformetam }\end{array}$ \\
\hline & Fentalamidas & Captafol, Captam \\
\hline \multirow{8}{*}{$\begin{array}{l}\text { Herbicidas } \\
\text { (combate às plantas } \\
\text { invasoras) }\end{array}$} & Inorgânicos & Arsenito de sódio, cloreto de sódio \\
\hline & Dinitrofenóis & Bromofenoxim, Dinoseb, DNOC \\
\hline & Fenoxiacéticos & CMPP, 2,4-D, 2,4,5-T \\
\hline & Carbamatos & Profam, Cloroprofam, Bendiocarb \\
\hline & Dipiridilos & Diquat, Paraquat, Difenzoquat \\
\hline & Dinitroanilinas & Nitralin, Profluralin \\
\hline & Benzonitrilas & Bromoxinil, Diclobenil \\
\hline & Glifosato & Round-up \\
\hline \multirow{2}{*}{$\begin{array}{l}\text { Desfoliantes } \\
\text { (combate às } \\
\text { folhas } \\
\text { indesejadas) }\end{array}$} & Dipiridilos & Diquat, Paraquat \\
\hline & Dinitrofenóis & Dinoseb, DNOC \\
\hline \multirow{3}{*}{$\begin{array}{l}\text { Fumigantes } \\
\text { (combate às bactérias } \\
\text { do solo) }\end{array}$} & $\begin{array}{l}\text { Hidrocarbonetos } \\
\text { Halogenados }\end{array}$ & Brometo de metila, cloropicrina \\
\hline & $\begin{array}{l}\text { Geradores de Metil- } \\
\text { isocianato }\end{array}$ & Dazomet, Metam \\
\hline & & Formaldeídos \\
\hline
\end{tabular}

Fonte: Anvisa, 2011

Os agrotóxicos são classificados, ainda, segundo seu poder tóxico (quadro 2). 
Revista Multidisciplinar do Nordeste Mineiro, v.2 2021/02

ISSN 2178-6925

Esta classificação é fundamental para o conhecimento da toxicidade de um produto, 
do ponto de vista de seus efeitos agudos. No Brasil, a classificação toxicológica está a cargo do Ministério da Saúde.

A ANVISA publicou, em 1ํ de agosto de 2019, a RE nํㅡ 2080/2019, com a reclassificação toxicológica dos produtos que já estavam no mercado. O novo marco regulatório para agrotóxicos atualiza e torna mais claros os critérios de avaliação e de classificação toxicológica dos produtos no Brasil. Para isso, foram ampliadas de quatro para cinco as categorias da classificação toxicológica, além da inclusão do item "não classificado", válido para produtos de baixíssimo potencial de dano, por exemplo, os produtos de origem biológica.

Quadro 2 - Classificação dos agrotóxicos de acordo com os efeitos à saúde humana

\begin{tabular}{|c|c|c|c|}
\hline Classe toxicológica & Toxicidade & DL50 & Faixa colorida \\
\hline $\mathrm{I}$ & $\begin{array}{l}\text { Produto } \\
\text { Extremamente } \\
\text { tóxico }\end{array}$ & $<=5 \mathrm{mg} / \mathrm{kg}$ & Vermelha \\
\hline & $\begin{array}{l}\text { Produto Altamente } \\
\text { tóxico }\end{array}$ & Entre 5 e 50 mg/kg & Vermelha \\
\hline II & $\begin{array}{l}\text { produto } \\
\text { Moderadamente } \\
\text { tóxico }\end{array}$ & $\begin{array}{llll}\text { Entre } & 50 \text { e } & 500 \\
\mathrm{mg} / \mathrm{kg} & & & \end{array}$ & Amarelo \\
\hline III & $\begin{array}{l}\text { Produto } \\
\text { tóxico }\end{array}$ & $\begin{array}{l}\text { Entre } 300 \text { e } 2000 \\
\mathrm{mg} / \mathrm{kg}\end{array}$ & Azul \\
\hline IV & $\begin{array}{l}\text { Produto Improvável } \\
\text { de Causar Dano } \\
\text { Agudo }\end{array}$ & $\begin{array}{l}\text { Entre } 500 \text { e } 5.000 \\
\mathrm{mg} / \mathrm{kg}\end{array}$ & Azul \\
\hline V & $\begin{array}{ll}\text { Produto Não } & \text { Nassificado - } \\
\text { Class }\end{array}$ & $\begin{array}{l}\text { Acima de } 5.000 \\
\mathrm{mg} / \mathrm{kg}\end{array}$ & Verde \\
\hline
\end{tabular}

Fonte: Brasil, 2019

A classificação toxicológica dos agrotóxicos é feita em função de estudos laboratoriais com exposição oral, dérmica e inalatória para determinar a CL50 e DL50 (Concentração Letal e Dose Letal, dadas em miligramas do produto tóxico por quilo de peso corporal necessários para matar $50 \%$ dos ratos ou outros animais expostos ao produto) (LONDRES, 2011).

A classificação ambiental é de responsabilidade do IBAMA, que avalia os agrotóxicos quanto ao potencial de periculosidade ambiental através de dados físicoquímicos e dados de toxicidade a organismos não alvos de diversos níveis tróficos. Essa classificação segue o mesmo padrão da classe toxicológica, conforme apresenta 
Revista Multidisciplinar do Nordeste Mineiro, v.2 2021/02

ISSN 2178-6925

o quadro 3: 
Quadro 3 - Classificação dos agrotóxicos quanto à periculosidade ambiental.

\begin{tabular}{|cc|}
\hline CLASSE & POTENCIAL DE PERICULOSIDADE \\
\hline I & Produto altamente perigoso \\
II & Produto muito perigoso \\
III & Produto perigoso \\
IV & Produto pouco perigoso \\
\hline
\end{tabular}

Fonte: Brasil, 2013

\section{O USO DE AGROTOXICOS NO BRASIL}

Os agrotóxicos tiveram origem após as grandes guerras mundiais, quando a indústria química fabricante de venenos então usados como armas químicas encontraram na agricultura um novo mercado para os seus produtos.

É importante contextualizar que a disseminação do uso dos agrotóxicos, que ocorre no período marcado pela extrema pobreza, provocou uma reação da Organização das Nações Unidas para a Agricultura e Alimentação, que com o objetivo de promover a segurança alimentar e a nutrição global e, engajada na luta pela erradicação da fome, passou a erguer a bandeira do uso dos agrotóxicos e demais insumos agrícolas como o principal caminho para se aumentar a produção de alimentos e, assim, atingir seu objetivo (COSTA; PIRES, 2016).

Neste sentido diversas políticas foram implementadas em todo o mundo para expandir e assegurar este mercado. A pesquisa agropecuária voltou-se para o desenvolvimento de sementes selecionadas para responder a aplicações de adubos químicos e agrotóxicos em sistemas de monoculturas altamente mecanizados, movimento que foi denominado de "Revolução Verde" (LONDRES, 2011).

No Brasil, este processo de modernização da agricultura foi impulsionado em 1965 pela criação do Sistema Nacional de Crédito Rural, que vinculava a obtenção de crédito agrícola à obrigatoriedade da compra de insumos químicos pelos agricultores, e também pela criação, em 1975, do Programa Nacional de Defensivos Agrícolas, no âmbito do II Plano Nacional de Desenvolvimento (PND), que proporcionou recursos financeiros para a criação de empresas nacionais e a instalação no país de subsidiárias de empresas transnacionais de insumos agrícolas (LONDRES, 2011).

De acordo com Peleaz et al (2010), outro fator importante que muito contribuiu para a enorme disseminação da utilização dos agrotóxicos no Brasil foi o 
marco regulatório defasado e pouco rigoroso que vigorou até 1989 (quando foi aprovada a Lei 7.802), que facilitou o registro de centenas de substâncias tóxicas, muitas das quais já proibidas nos países desenvolvidos.

Além disso, para promover o tão aclamado pacote tecnológico anunciado pela "Revolução Verde", foram concedidos incentivos fiscais, reduzindo a incidência e, em alguns casos, até mesmo isentando os produtos de tributos, provocando assim uma redução expressiva do preço final a ser pago pelo consumidor, tornando-o bem mais atraente ao potencial comprador e impulsionando sua venda (COSTA; PIRES, 2016).

Todos estes fatores provocaram uma grande pressão do mercado para a aquisição desses produtos, tendo como porta voz os agrônomos e técnicos, funcionários das casas comerciais e mesmo de alguns ligados ao poder público, que apresentavam os agrotóxicos como única alternativa ao aumento da produção e diminuição das perdas nas lavouras, tendo uma origem clara: os interesses das grandes indústrias de agroquímicos (PERES, ROZEMBERG, 2003).

O resultado foi uma expansão no uso de pesticidas não apenas quantitativa, mas também qualitativa, conforme aponta o IPEA (2019), que desde 1990 o Brasil apresenta uma taxa de utilização superior à de outros grandes produtores agrícolas, tendo como referência que em 1991 o consumo no país era cerca de sete vezes menos agrotóxicos que os Estados Unidos, enquanto em 2015 as quantidades no Brasil e nos Estados Unidos foram próximas, cada um respondendo por cerca de 10\% do consumo mundial.

\subsection{Legislação dos agrotóxicos no Brasil}

A primeira norma federal a versar sobre tema agrotóxicos no Brasil foi o Decreto Federal n. 024.414 , de 12 de abril de 1934, que de forma superficial no art. 52 , abordava apenas alguns aspectos de registro e fiscalização dos produtos, especialmente inseticidas e fungicidas (BRASIL, 1934).

Com o crescimento acentuado da utilização de produtos químicos na lavoura brasileira, na década de 70 profissionais de saúde e defensores do meio ambiente, agrônomos, consumidores, agricultores e ecologistas, começaram a pressionar o Congresso Nacional pela criação de uma nova lei em matéria de agrotóxicos, com o intuito de substituir o já ultrapassado Decreto de 1934 (BULL; HATHAWAY, 1986). 
O primeiro passo foi dado pela Constituição Federal de 1988 que em seu artigo 225 já estabelece alguns princípios que se aplicam à questão dos agrotóxicos, ao citar que:

Todos têm direito ao meio ambiente ecologicamente equilibrado, bem de uso comum do povo e essencial à sadia qualidade de vida. É dever do Poder Público e da coletividade defendê-lo e preservá-lo para as presentes e futuras gerações.

Para assegurar a efetividade desse direito, incumbe ao Poder Público controlar a produção, a comercialização e o emprego de técnicas, métodos e substâncias que comportem risco para a vida, a qualidade de vida e o meio ambiente (BRASIL, 1988)

Posteriormente, a fim de viabilizar a criação de um novo marco regulatório, no final da década de 1980, foi aprovada e sancionada a Lei Federal n. 9.802 , de 11 de julho de 1989, em um momento em que, devido a enormes pressões internacionais com foco sobre a Amazônia, ao medo dos militares de perder o controle sobre a floresta e suas fronteiras e à falta de apoio internacional, o governo brasileiro considerou estratégico aprovar um pacote de medidas pró meio ambiente (chamado "Nossa Natureza"), que incluía o Projeto de Lei sobre agrotóxicos (LONDRES, 2011).

A lei estabelece que compete à União a análise e aprovação de agrotóxicos, a partir das diretrizes e exigências dos órgãos ligados à saúde (Agência Nacional de Vigilância Sanitária - ANVISA), ao meio ambiente (Instituto Brasileiro do Meio Ambiente e dos Recursos Naturais Renováveis - IBAMA) e à agricultura (Ministério da Agricultura, Pecuária e Abastecimento - MAPA).

Nesse sentido, o art. $3^{\circ}$ indica que "o registro para novo produto agrotóxico, seus componentes e afins, será concedido se a sua ação tóxica sobre o ser humano e o meio ambiente for comprovadamente igual ou menor do que a daqueles já registrados, para o mesmo fim" (BRASIL, 1989).

Outro destaque da lei, é a proibição do registro de agrotóxicos quando houver demonstração de prejuízos ao meio ambiente, à saúde humana ou dos animais, possibilitando a impugnação do registro, por entidades de classe representativa de profissões ligada ao setor, partidos políticos com representação no Congresso Nacional e entidades legalmente constituídas com atuação voltada à defesa do consumidor, do meio ambiente e dos recursos naturais.

A lei também trata do assunto relacionado à devolução de embalagens vazias. 
vazias de agrotóxicos ao relento nas proximidades das lavouras, em beiras de córregos ou rios ou beiras de estrada. E apesar dos alertas, ainda há pessoas que reutilizam embalagens de agrotóxicos para acondicionar os mais diversos itens, até mesmo alimentos.

Deste modo, a Lei de Agrotóxicos determina que, no prazo de até um ano a partir da compra, os usuários de agrotóxicos são obrigados a devolver as embalagens vazias aos estabelecimentos comerciais onde foram comprados ou, quando possível, a um posto ou central de recolhimento de embalagens de agrotóxicos.

Já os estabelecimentos receptores devem dar a adequada destinação a tais embalagens, assumindo a responsabilidade, também, pelos produtos apreendidos em fiscalizações e pelos impróprios à utilização ou em desuso (obsoletos), sob pena de responsabilização administrativa, civil e criminal (art. 14, "e", da Lei $n^{\circ} 7.802 / 89$ ).

A lei também abrange o cadastro compulsório de produtores, comerciantes e aplicadores dos produtos nos órgãos competentes dos Estados ou Municípios, no intuito de maior rastreabilidade das infrações causadas pelos agrotóxicos; a criação de normas e padrões das embalagens, assim como as normas, padrões, e instruções dos rótulos dos produtos; a atribuição de responsabilidades administrativas por qualquer dano causado pelos agrotóxicos (BRASIL, 1989).

Um ponto importante da lei e terma do presente estudo está expresso no art.13: "A venda de agrotóxicos e afins aos usuários será feita através de receituário próprio, prescrito por profissionais legalmente habilitados, salvo casos excepcionais que forem previstos na regulamentação desta Lei".

Segundo a Lei de Agrotóxicos, a compra destes produtos só pode ocorrer com a apresentação do chamado Receituário Agronômico - o equivalente a uma "receita médica", exigida para a compra de medicamentos tarjados. O Receituário Agronômico deve ser emitido por profissional legalmente habilitado (engenheiro agrônomo, engenheiro florestal ou técnico agrícola) (LONDRES, 2011).

Segundo o Art. 65 do Decreto 4.074/2002, que regulamenta a Lei de Agrotóxicos, a receita deve ser específica para cada cultura ou problema e conter informações como o diagnóstico, doses de aplicação e quantidades totais a serem adquiridas do produto, época de aplicação, intervalo de segurança, entre outras. Em tese, para que um profissional possa emitir um receituário agronômico, ele deve antes visitar a propriedade rural ou examinar amostra do material infectado. 


\subsection{Receituário agronômico}

De acordo com Alves Filho (2000), a implantação do sistema de receituário agronômico no Brasil, caracterizada atualmente como exigência legal de autorização escrita para a comercialização e aplicação de agrotóxicos, foi resultado de um longo processo de discussão na comunidade técnica do meio agronômico, iniciada por profissionais atuantes no estado do Rio Grande do Sul, em torno dos problemas identificados pelo uso indiscriminado desses insumos gerando os impactos ao ambiente e à saúde humana.

Desde o início da década de 70 as preocupações com o uso indiscriminado de produtos fitossanitários eram motivo de discussões, em razão do crescente número de ocorrências de acidentes com agricultores e agressões ao ambiente registradas no nosso país, especialmente no Rio Grande do Sul. Esse fato motivou uma recomendação de restrição a vendas de produtos fitossanitários na "I Convenção Regional do Centro de Estudos de Toxicologia do Rio Grande do Sul" realizada em 3 de agosto de 1974. Nela os convencionais propunham um sistema de bloqueio regional para produtos fitossanitários altamente tóxicos ou persistentes e a comercialização desses através de receita agronômica assinada por um agrônomo (ALVES FILHO, 2000).

A criação do chamado Receituário Agronômico, com previsão expressa no art. 13 da Lei 7.802/89, regulamentada pelo Decreto 4.074, de 4 de janeiro de 2002, é reflexo direto dessa preocupação com a construção de um regramento jurídico destinado ao controle do uso de agrotóxicos na atividade agrícola.

Nesse sentido, pondera Alves Filho (2000) que a prescrição técnica formalizada, como instrumento legal obrigatório para a compra desses insumos, representou um dos caminhos institucionais construídos no Brasil para se tentar reverter os graves problemas ambientais e de saúde públicos desenhados pelo uso indiscriminado de agrotóxicos nas atividades agropecuárias e florestais.

Neste sentido, segundo o CREA (2010):

A aplicação de um agrotóxico, prevista e autorizada por um uma receita agronômica é uma das etapas de um planejamento fitossanitário para a cultura. Este planejamento deve prever várias etapas iniciais, englobando outras estratégias de manejo integrado, com práticas de controle cultural, físico e biológico, quando possível. $\mathrm{Na}$ etapa de controle químico, 0 
Revista Multidisciplinar do Nordeste Mineiro, v.2 $2021 / 02$

ISSN 2178-6925

profissional deve escolher a melhor opção dentre todas as alternativas 


\section{$2021 / 02$}

ISSN 2178-6925

válidas, considerando para efeito de comparação o custo, a eficiência, a segurança (ao aplicador, consumidor e ambiente), a seletividade, a compatibilidade, a praticabilidade e a praticidade. O receituário agronômico envolve todo o processo, e a emissão da receita é sua parte final e condição indispensável para a aquisição do produto (CREA, 2010, P.15).

Assevera Vaz (2006), que o Receituário Agronômico, em sua essência, consiste em uma metodologia utilizada para diagnóstico do problema fitossanitário que está atacando determinada cultura e a eventual prescrição do agrotóxico adequado, quando necessário o tratamento químico.

Desta forma, entende-se por Receita ou Receituário a prescrição e orientação técnica para utilização de agrotóxico ou afim, por profissional legalmente habilitado (Decreto nำ4.074, de 4 de janeiro de 2002). Dessa forma, os agrotóxicos e afins só poderão ser comercializados diretamente ao usuário, mediante apresentação de receituário próprio (ALMEIDA; SOUZA; BARROS, 2015).

Conforme previsão do Decreto Federal 4.074/2002, art. 66, a receita, específica para cada cultura ou problema, deverá conter, necessariamente:

I - nome do usuário, da propriedade e sua localização;

II - diagnóstico;

III - recomendação para que o usuário leia atentamente o rótulo e a bula do produto;

IV - recomendação técnica com as seguintes informações:

a) nome do(s) produto(s) comercial(ais) que deverá(ão) ser utilizado(s) e de eventual(ais) produto(s) equivalente(s);

b) cultura e áreas onde serão aplicados;

c) doses de aplicação e quantidades totais a serem adquiridas;

d) modalidade de aplicação, com anotação de instruções específicas,

quando necessário, e, obrigatoriamente, nos casos de aplicação aérea;

e) época de aplicação;

f) intervalo de segurança;

g) orientações quanto ao manejo integrado de pragas e da resistência;

h) precauções de uso; e

i) orientação quanto à obrigatoriedade da utilização de EPI (Equipamento de Proteção Individual).

$\mathrm{V}$ - data, nome, CPF e assinatura do profissional que a emitiu, além do seu registro no órgão fiscalizador do exercício profissional.

Importante mencionar, que na opinião de Machado (2012), o receituário pode ser comparado a uma receita médica, mas no lugar de examinar o corpo de uma pessoa para se verificar a doença existente e passar a medicação adequada para os sintomas apresentados, a produção agrícola que é estudada a fim de serem prescritos 
agrotóxico deve ser precedida de diagnóstico, não podendo ser realizada se não houver manifestação da "doença".

Conforme dispõe Almeida, Souza e Barros (2015) ao realizar o diagnóstico, o profissional responsável deverá proceder uma avaliação do ambiente em questão (área de cultivo ou instalações), descrevendo qual organismo (praga) que está causando o problema, relatando o nome comum e o nome cientifico (inseto, doença ou planta daninha), sendo necessária a realização de amostragem, considerando cada caso, para determinação da intensidade do problema (infestação/incidência da praga).

Neste contexto, a receita deve ser resultado da efetiva participação do profissional que assume a responsabilidade pela necessidade e pelos resultados do tratamento, desde que o agricultor respeite as recomendações contidas na receita e demais orientações prestadas pelo profissional que não são possíveis de inclusão no receituário, visto que o mesmo não substitui o contato frequente e orientações agronômicas constantes, necessárias ao sucesso dos empreendimentos agrícolas. Portanto, não se exige receita para legalizar a venda de agrotóxicos, mas sim para o uso (CREA, 2010).

Não se trata, portanto, de apenas emitir um documento. A tarefa exige conhecimento técnico amplo e dedicação ao caso concreto submetido à análise, especialmente tendo em vista a complexidade que marca o ambiente rural, além disso é extremamente necessária a participação ativa e constante do profissional que deve estar presente nos locais a serem diagnosticados. (LONDRES, 2011).

A presença do profissional vai determinar o uso seguro do produto através da verificação in loco da capacidade do usuário em manusear os agrotóxicos sem comprometer a sua saúde, de sua família e de seus vizinhos, bem como pressupõe uma avaliação do entorno da área de aplicação para verificação de riscos ambientais e de danos colaterais aos cultivos e criações de áreas contíguas (MOREIRA; BRAGA, 2016).

A negligência do profissional habilitado quanto à prescrição da receita agronômica com diagnóstico falso (cultura inexistente), prescrição da receita para controle de praga ou doença quando a lavoura ainda não foi implantada, prescrição da receita agronômica de maneira genérica, errada, displicente ou indevida, quando 
Revista Multidisciplinar do Nordeste Mineiro, v.2 2021/02

ISSN 2178-6925

ainda, prescrever receita agronômica sem constar precauções de uso ou 
mesmo assinar receita agronômica sem a mesma estar preenchida, pode gerar penalidades constantes na legislação de agrotóxicos, bem como responder junto ao CREA por acobertamento e Ética Profissional (CREA , 2010).

A receita errada está relacionada à imperícia do profissional que, ao emiti-la, não emprega corretamente os conhecimentos técnico-científicos próprios de sua formação. Neste contexto, o erro pode ser tanto de diagnóstico quanto relacionado às recomendações técnicas sobre o produto receitado, no que se refere à quantidade, dosagem, periodicidade, modo de aplicação, etc. (VAZ, 2006).

A receita displicente está relacionada à negligência, sendo aquela decorrente do desleixo do profissional no cumprimento das ordens do regulamento, voltada ao objetivo do controle de pragas e doenças ou à produção de alimentos sadios, sem sequelas significativas para o meio ambiente (MACHADO, 2012).

Portanto, a exigência de receituário agronômico para a venda de agrotóxicos representou um avanço, pois pode possibilitar a escolha racional do agrotóxico mais adequado a determinada cultura, ensinar técnicas alternativas e supletivas ao uso dos químicos, contribuir para conscientizar acerca dos possíveis danos advindos do uso, trazer precauções em relação ao ambiente de trabalho rural, valorizar aqueles que atuam como agrônomos (especialmente os que detêm conhecimentos sobre agrotóxicos menos perigosos) e criar um ambiente informativo mais acessível para os trabalhadores rurais (GEREMIA, 2011, p. 54).

\section{CONSIDERAÇÕES FINAIS}

Tendo em vista os aspectos observados, o crescimento do uso de produtos agrotóxicos no Brasil provocou reações de diversos setores da sociedade, culminando em uma pressão sobre os órgãos governamentais no sentido de estabelecer em controle ma rígido quanto a aplicação, registro, embalagens e a venda de tais produtos.

Dessa forma, no âmbito da legislação, dentre os vários dispositivos reguladores, o receituário agronômico é um dos instrumentos disponibilizados para controlar o uso indiscriminado dos agrotóxicos, preservando assim o meio ambiente e ao mesmo tempo contribuindo com a saúde dos usuários. 
Por isso, a prescrição exige ética, compromisso e responsabilidade, para inibir o interesse puramente comercial, privilegiando o aspecto técnico que possa atender efetivamente a área do cultivo, terminando a correta aplicação.

Portanto, demonstrou-se que o receituário agronômico é um importante instrumento legal capaz de possibilitar a utilização segura e adequada dos produtos.

\section{REFERÊNCIAS}

ALMEIDA, Raul Porfírio de; SOUSA, Raimundo Nonato Lopes de; BARROS, Luiz Carlos de Sá. Receituário Agronômico - Prescrição Técnica de Agrotóxicos / [ Raul Porfírio de Almeida... et al.] - João Pessoa, PB Brasil: CREA-PB, 2015.

ALVES FILHO, Jose prado. Receituário agronômico: a construção de um instrumento de apoio à gestão dos agrotóxicos e sua controvérsia. Dissertação (Mestrado). Programa de Pós Graduação em Ciência Ambiental - Universidade de São Paulo, 2000.

ANTUNES, Paulo de Bessa. Direito Ambiental. 17 ed. São Paulo: Atlas, 2015.

BRASIL. Decreto no 24.114, de 12 de abril de 1934. Aprova o Regulamento de Defesa Sanitária Vegetal. Diário Oficial da União, Brasília, DF, 18 maio 1934. Disponível em: <http://www.planalto.gov.br/ccivil_03/decreto/19301949/D24114.htm>. Setembro de 2020.

.Constituição da República Federativa do Brasil de 1988. Senado

Federal. Brasília, DF, 05 out. 1988. Disponível em: <http://www.planalto.gov.br/ccivil_03/constituicao/constituicaocompilado.htm>.

Acesso em setembro de 2020.

.Decreto no 4.074, de 4 de janeiro de 2002. Regulamenta a Lei no 7.802/89 (Lei Federal dos Agrotóxicos). Diário Oficial da União, Brasília, DF, 08 jan. 2002.

Disponível

em:

$<$ http://www.mma.gov.br/port/conama/legiabre.cfm?codlegi=515>. Acesso em setembro de 2020.

. Lei no 7.802, de 12 de julho de 1989 (lei federal dos agrotóxicos).

Diário Oficial da União, Brasília, DF, 12 jul. 1989. Disponível em: <http://www.planalto.gov.br/ccivil_03/LEIS/L7802.htm>. Acesso em setembro de 2020.

Ministério da Saúde/Agência Nacional de Vigilância Sanitária/ RESOLUÇÃO-RE № 2.080, DE 31 DE JULHO DE 2019. Reclassificação toxicológica de acordo com o disposto na Resolução da Diretoria Colegiada - RDC nํㅡㄴ 294, de 29 de julho de 2019, baseada nos critérios definidos pelo Sistema Globalmente Harmonizado de Classificação e Rotulagem de Produtos Químicos (GHS). 
BULL, David; HATHAWAY, David. Pragas e venenos: agrotóxicos no Brasil e no terceiro mundo. Original: Oxfam- Oxford, Inglaterra, 1982. Trad. e ampliado: Vozes, Petrópolis, 1986.

CENTRO ESTUDOS AVANÇADOS DE ECONOMIA APLICADA - CEPEA - ESALQ. Gerência Geral de Toxicologia. Programa de Análise de Resíduos de Agrotóxicos em Alimentos (PARA): Relatório de Atividades de 2010. Brasília, 2011. Disponível em:<http://portal.anvisa.gov.br/wps/wcm/connect/b380fe004965d38ab6abf74ed7589 1ae/Relat\%C3\%B3rio+PARA+2010+-+Vers\%C3\%A30+Final.pdf?MOD=AJPERES>. Acesso em outubro de 2020.

COSTA, Letícia Fancelli; PIRES, Gabriel Lino de Paula. Análise histórica sobre a agricultura e o advento do uso de agrotóxicos no Brasil. Encontro de Iniciação Científica - ETIC 2016. Disponível em http://www.intertemas.toledoprudente.edu.br. Acesso em setembro de 2020. ,

CREA- Conselho Regional de Engenharia, Arquitetura e Agronomia. Manual de orientação sobre Receituário agronômico, uso e Comércio de agrotóxicos. Curitiba/PR, 2010.

EMPRESA BRASILEIRA DE PESQUISA AGROPECUÁRIA SISTEMAS DE PRODUÇÃO (EMBRAPA). O mundo rural no Brasil do século 21 : a formação de um novo padrão agrário e agrícola / Antônio Márcio Buainain, Eliseu Alves, José Maria da Silveira, Zander Navarro, editores técnicos. - Brasília, DF : Embrapa, 2014. 1182 p. : il. color. ; $18,5 \mathrm{~cm} \times 25,5 \mathrm{~cm}$.

GASQUES, J. G.; BASTOS, E. T.; BACCHI, M. R. P.; VALDÉS, C. Produtividade total dos fatores e transformações da agricultura brasileira: análise dos dados dos Censos Agropecuários. In: DOSSA, D.; NAVARRO, Z. (Ed.). A agricultura brasileira: desempenho recente, desafios e perspectivas. Brasília, DF: Mapa; Ipea, 2010. No prelo.

GEREMIA, Barbara. Agrotóxicos: o emprego indiscriminado de produtos químicos no ambiente de trabalho rural e a responsabilização por danos à saúde. Dissertação de Mestrado, Universidade de Caxias do Sul, 2011. Disponível em:<https://repositorio.ucs.br/xmlui/bitstream/handle/11338/600/Dissertacao\%20Bar bar\%20Geremia.pdf;jsessionid=54F477352AC82776494BE1CCAC5A93C8?sequenc $\mathrm{e}=1>$. Acesso em setembro de 2020.

Instituto de Pesquisa Econômica Aplicada - IPEA. Agrotóxicos no Brasil: padrões de uso, política da regulação $E$ prevenção da captura regulatória1 Brasília, setembro de 2019.

KARAN, Décio et al. Agrotóxicos / Décio Karam ... [et al.]. -- Sete Lagoas : Embrapa Milho e Sorgo, 2015. 28 p. : il. -- (Documentos / Embrapa Milho e Sorgo, ISSN 1518-4277; 192) 
LONDRES, Flavia. Agrotóxicos no Brasil: um guia para ação em defesa da vida. Rio de Janeiro: AS-PTA - Assessoria e Serviços a Projetos em Agricultura Alternativa, 2011.

MACHADO, Paulo Affonso Leme. Direito ambiental brasileiro. 18. ed. São Paulo: Malheiros, 2010.

MELO, Roseli Freire de et al. Pesticidas e seus impactos no ambiente. IN: In: BRITO, L. T. de L.; MELO, R. F. de; GIONGO, V. (Ed.). Impactos ambientais causados pela agricultura no Semiárido brasileiro. Petrolina: Embrapa Semiárido, 2010.

MOREIRA, Patrícia Almeida Barroso; FRAGA, Matheus Mazon. Uso da prescrição de agrotóxicos no Brasil: um estudo de Caso na região de tubarão - SC. Extensio: R. Eletr. de Extensão, ISSN 1807-0221 Florianópolis, v. 13, n. 23, p.71-82, 2016. Disponível em https://periodicos.ufsc.br/index.php/extensio/article/view/18070221.2016v13n23p71. Acesso em setembro 2020

PELEAZ,Victor et al. A regulamentação dos agrotóxicos no Brasil: entre o poder de mercado e a defesa da saúde e do meio ambiente. Revista de Economia, v. 36, n. 1 (ano 34), p. 27-48, jan./abr. 2010. Editora UFPR 2. Disponível em http://www.revistas.ufpr.br. Acesso em outubro de 2020.

PERES, F.; ROZEMERG, B. É veneno ou é remédio? - os desafios da comunicação rural sobre agrotóxicos. In PERES, F.; MOREIRA, J. C. (orgs.). É veneno ou é remédio? Agrotóxicos, saúde e ambiente. Rio de Janeiro: Fiocruz, 2003. p. 327- 346.

SAMBUICHI, Regina Helena Rosa et al. a sustentabilidade ambiental daagropecuária brasileira: impactos, políticas públicas e desafios. Texto para discussão / Instituto de Pesquisa Econômica Aplicada.- Brasília : Rio de Janeiro : Ipea , 2012.

SCOLARI, Dante D.G. Produção agrícola mundial: o potencial do Brasil. Embrapa, 2006. Disponível emhtto:// https://www.embrapa.br/busca-de-publicacoes//publicacao/417182/producao-agricola-mundial-o-potencial-do-brasil. Acesso em setembro de 2020.

VAZ, Paulo Afonso Brum. O Direito Ambiental e os agrotóxicos: responsabilidade civil, penal e administrativa. Porto Alegre: Livraria do Advogado, 2006.

TAVELLA, Leonardo Barreto et al. O uso de agrotóxicos na agricultura e suas consequências Toxicológicas e ambientais. ACSA - Agropecuária Científica no Semi-Árido, v.07, n 02 abril/junho 2011 p. 06 - 12 Disponível em http://www.cstr.ufcg.edu.br/acsa. Acesso em setembro de 2020. 
Atividade: Trabalho de Conclusão de Curso - Artigo.

Curso: Agronomia Período: 10 Semestre: 2ำ Ano: 2020

Professor (a): Pedro Emílio Amador Salomão

\section{Acadêmico: Kárisma Rodrigues Pêgo}

\begin{tabular}{|c|c|c|}
\hline Tema: Artigo Final- & & Assinatura do aluno \\
\hline Data(s) do(s) atendimento(s) & Horário(s) & \\
\hline 03/09/2020 & $13: 30-14: 50$ & KARISMA Rodrígues Pêgo \\
\hline $13 / 09 / 2020$ & $13: 00-14: 00$ & KÁRISMA Rodrigues Pêgo \\
\hline $19 / 10 / 2020$ & $14: 00-15: 05$ & KÁRISMA Rodrigues Pêgo \\
\hline $03 / 10 / 2020$ & $18: 10-19: 00$ & KÁISMA Rodrigues Pêgo \\
\hline $10 / 11 / 2020$ & $13: 20-14: 00$ & KÁRISMA Rodrígues Pêgo \\
\hline \multicolumn{3}{|l|}{ Descrição das orientações: } \\
\hline \multicolumn{3}{|l|}{ Auxílio na escrita do artigo. } \\
\hline
\end{tabular}

\section{FICHA DE ACOMPANHAMENTO INDIVIDUAL DE ORIENTAÇÃO DE TCC}

Considerando a concordância com o trabalho realizado sob minha orientação, AUTORIZO 0 DEPÓSITO do Trabalho de Conclusão de Curso da Acadêmica Kárisma Rodrigues Pêgo.

\section{Atalo Ôtunes Pereíra Lima}




$$
\text { 2021/02 }
$$

ISSN 2178-6925

\section{CopySpider-report-20201113.pdf $\downarrow$ Baixar $\quad$ Imprimir $@$ Salvar no OneDrive}

\section{Arquivos}

artigo receituario.doc $\mathrm{X}$

https://portal.fiocruz.br/sites/portal.fiocruz.br/files/documentos/c

ap 01 veneno ou remedio.pdf

artigo receituario.docx $\mathrm{X}$

http://www.planalto.gov.br/ccivil 03/leis/7802.htm

artigo receituario.docx $X$

https://docplayer.com.br/17004096-Intoxicacoes-por-

agrotoxicos-no-brasil-0-papel-da-vigilancia-em-saude.html

artigo receituario.docx $X$

https://apmtsp.org.br/agrotoxicos

artigo receituario.doc $X$

https://www.mma.gov.br/seguranca-quimica/gestao-das-

substancias-quimicas/produtos-agrotóxicos.html

artigo receituario.doc $X$

http://www.cpatsa.embrapa.br:8080/sistema_producao/spuva/a

grotoxicos.html

artigo receituario.docx $X$

https://www.passeidireto.com/arquivo/74414142/intoxicacoes-

por-agrotoxicos-no-brasil-o-papel-da-vigilancia-em-saude/2

artigo receituario.docx $X$

https://querobolsa.com.br/unipac/cursos/minas-gerais--teofilo-

otoni

artigo receituario.doc $\mathrm{X}$

https://www.docsity.com/pt/seguranca-ecologica/5320370

artigo receituario.docx $X$

httos://www.unioac.br

\section{Termos comuns Similaridade} 367
- Parece que o documento não existe ou não pode ser acessado. HTTP response code: 403 - Server returned HTTP response code: 403 for URL: https://www.docsity.com/pt/segurancaecologica/5320370 